\title{
Feasible induction of coronary artery vasospasm occurred during cardiac catheterization in a microminipig
}

\author{
Suchitra MATSUKURA ${ }^{1)}$, Yuji NAKAMURA ${ }^{1)}$, Hiroshi OHARA ${ }^{2)}$, Xin $\mathrm{CAO}^{1)}$, Takeshi WADA ${ }^{1)}$, \\ Hiroko IZUMI-NAKASEKO ${ }^{1)}$, Kentaro ANDO ${ }^{1)}$, Yoshikiyo AKASAKA ${ }^{3)}$ and Atsushi SUGIYAMA ${ }^{1) *}$ \\ ${ }^{1)}$ Department of Pharmacology, Faculty of Medicine, Toho University, 5-21-16 Omori-nishi, Ota-ku, Tokyo 143-8540, Japan \\ 2) Division of Cardiovascular Medicine, Department of Internal Medicine, Faculty of Medicine, Toho University, 6-11-1 Omori-nishi, \\ Ota-ku, Tokyo 143-8541, Japan \\ ${ }^{3)}$ Department of Pathology, Faculty of Medicine, Toho University, 5-21-16 Omori-nishi, Ota-ku, Tokyo 143-8540, Japan
}

(Received 15 July 2015/Accepted 8 January 2016/Published online in J-STAGE 23 January 2016)

ABSTRACT. A 14 month-old intact microminipig, weighing $8 \mathrm{~kg}$, showed ST-segment elevation in A-B lead electrocardiogram during cardiac catheterization followed by ventricular tachycardia, which degenerated into ventricular fibrillation. Although a direct current defibrillation of $360 \mathrm{~J}$ was applied, ventricular tachycardia re-occurred for another 2 times and the direct defibrillation was repeated. After returning to normal sinus rhythm, a marked ST-segment elevation was still observed on leads II, III and aVF together with a remarkable decrease in contractility of inferior wall. The heart was excised for precise macroscopic and histological examinations, but there was no dissection, embolus or thrombus in the coronary arteries. These findings suggest that right coronary artery vasospasm could have caused the ischemic attack, leading to lethal arrhythmias.

KEY WORDS: coronary spastic angina, defibrillator, sudden cardiac death

doi: 10.1292/jvms.15-0426; J. Vet. Med. Sci. 78(5): 873-876, 2016

A miniature pig has been used in biomedical research as a laboratory animal, because of its similarities to humans in many of the organs including cardiovascular, urinary, integumentary and digestive systems [11]. However, there are many reports describing that pigs are generally susceptible to stress, resulting in the onset of various types of illnesses [3, 8]. Microminipig is the smallest pig in the world optimized for life-science research by Fuji Micra Inc. (Fujinomiya, Japan) [5, 6, 10]. Recently, we encountered one case of microminipig showing myocardial ischemic attack leading to the onset of lethal arrhythmias during cardiac catheterization. Since the onset mechanism of a sudden death in swines including miniature pigs or microminipigs still remains unknown, we analyzed this case to clarify possible pathophysiology that caused ischemic attack.

Male microminipigs were obtained from Fuji Micra Inc. to evaluate the cardiovascular effects of new chemical compounds. The experiment was approved by the Animal Research Committee for Animal Experimentation of Toho University (No. 15-52-275) and performed in accordance with the Guidelines for the Care and Use of Laboratory Animals of Toho University. The microminipig of 14-month-old, weighing $8 \mathrm{~kg}$, was pre-anesthetized by an intramuscular injection of ketamine $\left(16 \mathrm{mg} / \mathrm{kg}\right.$; Ketalar ${ }^{\circledR}$, Daiichi Sankyo

*Correspondence to: Sugiyama, A., Department of Pharmacology, Faculty of Medicine, Toho University, 5-21-16 Omori-nishi, Otaku, Tokyo 143-8540, Japan.

e-mail: atsushi.sugiyama@med.toho-u.ac.jp

(C)2016 The Japanese Society of Veterinary Science

This is an open-access article distributed under the terms of the Creative Commons Attribution Non-Commercial No Derivatives (by-nc-nd) License $<$ http://creativecommons.org/licenses/by-nc-nd/4.0/>.
Co., Ltd., Tokyo, Japan)/xylazine (1.6 mg/kg; Celactal ${ }^{\circledR}$, Bayer Health Care Co., Ltd., Osaka, Japan). Propofol (Frensenius Kabi Co., Ltd., Tokyo, Japan) was intravenously administered in a dose of $10 \mathrm{mg} /$ body over $20 \mathrm{sec}$ through the superficial auricular vein. Endotracheal intubation was performed with the $5 \mathrm{~mm}$ cuffed tube. Anesthesia was maintained with $1 \%$ halothane (Fluothane ${ }^{\circledR}$, Takeda Pharmaceutical Co., Ltd., Osaka, Japan) vaporized with 100\% oxygen with volume-limited ventilator (SN-480-3; Shinano Manufacturing Co., Ltd., Tokyo, Japan) in order to examine the utility of microminipigs for assessing drug-induced QT-interval prolongation in comparison with that of dogs. A tidal volume and respiratory rate were set at $10 \mathrm{~m} l / \mathrm{kg}$ and 15 strokes/min, respectively. The microminipig was placed in supine position. A-B lead electrocardiogram was obtained by using a polygraph system (RM-6000; Nihon Kohden Co., Ltd., Tokyo, Japan). Heparin calcium in a dose of $100 \mathrm{IU} / \mathrm{kg}$ (Caprocin $^{\circledR}$, Sawai Pharmaceutical Co., Ltd., Osaka, Japan) was intravenously administered to prevent blood clotting. A clinically available 6F-size, catheter-sheath set (FAST$\mathrm{CATH}^{\circledR}$, 406108; St. Jude Medical Daig Division, Inc., Minnetonka, MN, U.S.A.) was inserted into the left femoral artery to measure blood pressure. A 4F-size, catheter-sheath set (RADIOFOCUS ${ }^{\circledR}$, RR-A40G10A; Terumo Corporation, Tokyo, Japan) was inserted into the left femoral vein to obtain blood sample. After the catheter-sheath set was inserted, halothane was decreased to $0.5 \%$. After $1 \mathrm{hr}$ of stabilization, the blood pressure and heart rate were $65 / 35 \mathrm{mmHg}$ and $50 \mathrm{bpm}$, respectively. In our database on microminipigs, the blood pressure and heart rate (measn $\pm \mathrm{SD}, \mathrm{n}=40$ ) were 81 $\pm 16 / 52 \pm 12 \mathrm{mmHg}$ and $75 \pm 20 \mathrm{bpm}$, respectively, under the currently used experimental condition, indicating that the blood pressure and heart rate in this case were relatively low, 
A

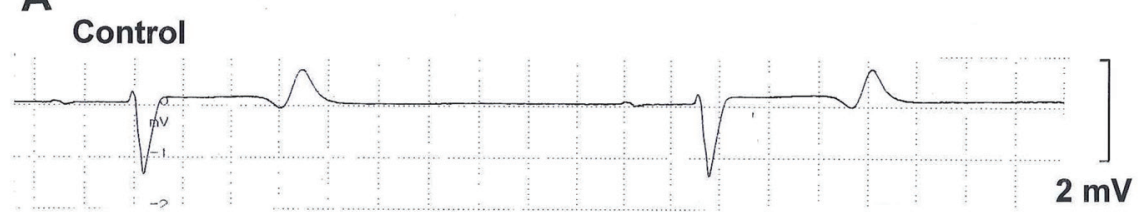

After insertion of Amplatz catheter

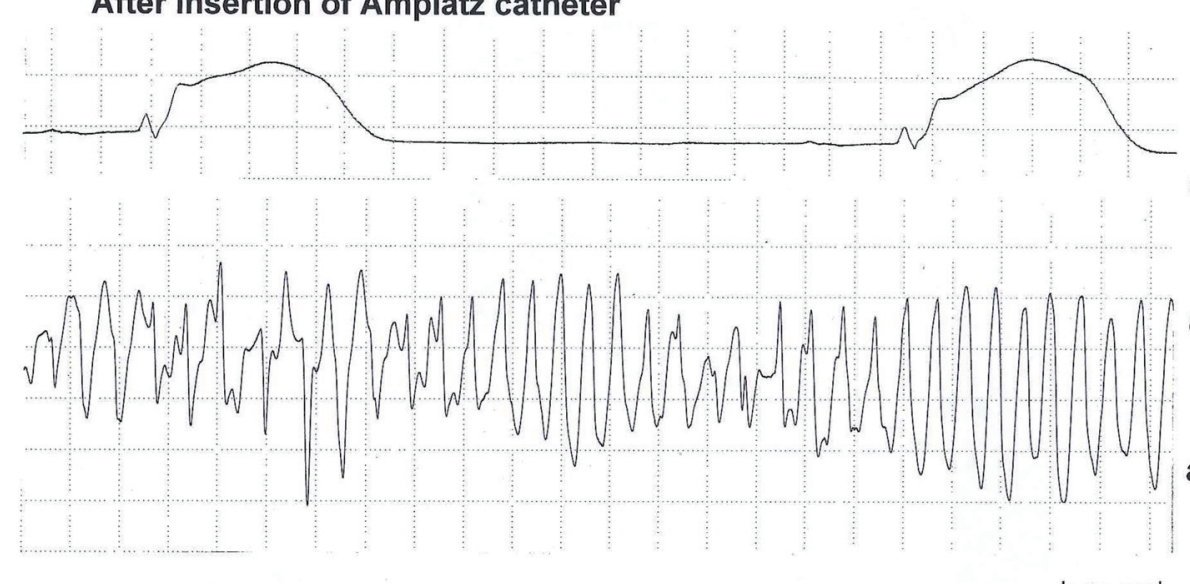

$200 \mathrm{~ms}$
B

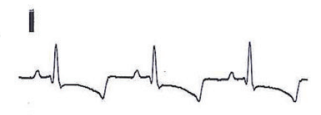

II

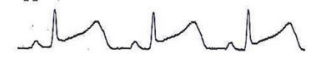

III

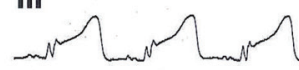

aVR

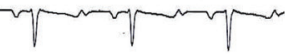

aVL

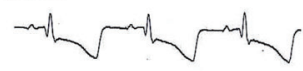

aVF

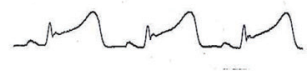

$1 \mathrm{~s}$

Fig. 1. Electrocardiograms during the study. (A) The upper panel shows the electrocardiogram (A-B lead) before insertion of Amplatz catheter via the femoral artery. Middle panel represents ST-segment elevation about 5 min after the insertion of Amplatz catheter. The lower panel shows polymorphic ventricular tachycardia that was observed within 1 min after the onset of STsegment elevation. (B) Limb-leads electrocardiogram revealed ST-segment elevation in II, III and aVF, indicating transmural ischemia in the inferior myocardial wall. The vertical scale of $2 \mathrm{mV}$ in the figure is common to $\mathrm{A}$ and $\mathrm{B}$.

but each value was more than the levels of mean $-1.5 \mathrm{SD}$. A 5F-size, pig-tail catheter (Cordis Corporation, Fremont, CA, U.S.A.) was inserted through catheter-sheath placed at the left femoral artery, tip of which was set out to be placed in the left ventricle to measure the left ventricular pressure. However, we could not place the pig-tail catheter into the left ventricle even under fluoroscopic guidance, because of the difficulty for its tip to pass through the aortic valve. About 10 min after the removal of it, we alternatively inserted a $5 \mathrm{~F}$ size; external diameter $1.7 \mathrm{~mm}$ "Amplatz catheter for right coronary artery" (Cordis Corporation) into the left ventricle under fluoroscopic guidance by using a guide wire technique and then started to monitor the left ventricular pressure.

About 5 min later, we noticed that the ST-segment in the A-B lead electrocardiogram was elevated (Fig. 1A, middle panel). Then, polymorphic ventricular tachycardia occurred within $1 \mathrm{~min}$ after the onset of ST-segment elevation (Fig. 1A, lower panel), which degenerated into ventricular fibrillation. The direct current defibrillation of $360 \mathrm{~J}$ was applied, which terminated the ventricular fibrillation, returning to a normal sinus rhythm. About $5 \mathrm{~min}$ after the initial direct current defibrillation, the blood pressure and heart rate were $32 / 21 \mathrm{mmHg}$ and $33 \mathrm{bpm}$, respectively. Next, atropine sulfate hydrate $(0.5$ mg; Mitsubishi Tanabe Pharma Corporation, Osaka, Japan) and adrenaline $\left(0.1 \mathrm{mg}\right.$; Bosmin ${ }^{\circledR}$, Daiichi Sankyo Co., Ltd.) were intravenously administered to increase the heart rate and blood pressure, respectively. However, in less than $1 \mathrm{~min}$ after the drugs were administered, ventricular tachycardia re-occurred, which degenerated into ventricular fibrillation. The direct current defibrillation of $360 \mathrm{~J}$ was applied another 2 times, and the latest one terminated the ventricular fibrillation, resulting in a return to normal sinus rhythm. The blood pressure and heart rate became 100/81 $\mathrm{mmHg}$ and $120 \mathrm{bpm}$, respectively. We recorded limb-lead electrocardiogram to clarify the ischemic lesion in the heart by using electrocardiogram recorder (FCP-4101; Fukuda Denshi Co., Ltd., Tokyo, Japan). A marked ST-segment elevation was observed in leads II, III and aVF, whereas ST-segment depression was found in leads I and aVL (Fig. 1B), suggesting the presence of the transmural ischemia in the inferior wall. Transthoracic echocardiography (Vivid $i^{\circledR}$ cardiovascular ultrasonic scanner, GE Medical Systems, Tokyo, Japan) was performed to confirm the abnormality of wall motion of the ventricles. Echocardiographic images in the long- and short-axis views are depicted in Fig. 2. Severe hypokinesis was observed in the inferior wall, and we decided to terminate this experiment.

In order to clarify the pathophysiology occurred in this animal, $1 \mathrm{hr}$ after the echocardiography, we sacrificed the microminipig with injection of $20 \mathrm{ml}$ of $\mathrm{KCl}$ in $6 \mathrm{M}$ solution (Wako Pure Chemical Industries, Ltd., Osaka, Japan). The heart was excised and immediately fixed in $4 \%(\mathrm{w} / \mathrm{v})$ 


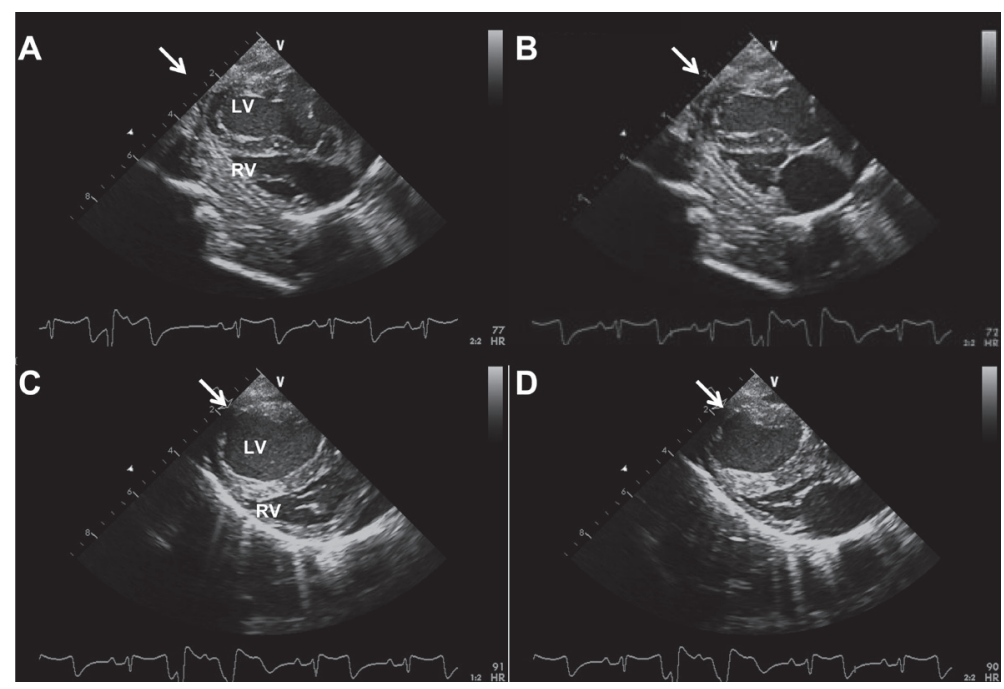

Fig. 2. Echocardiographic images after ST-segment elevation. Arrows indicate the region of contractile dysfunction. Parasternal long-axis at end-diastole (A) and at end-systole (B); and parasternal short-axis at end-diastole (C) and at end-systole (D). LV: left ventricle, and RV: right ventricle.

paraformaldehyde solution (Wako Pure Chemical Industries, Ltd.). The heart later underwent detailed necropsy. Macroscopic analysis indicated that there was no dissection, embolus or thrombus in the right or left coronary artery. A microscopic study for whole heart also showed no histological change of inflammation, necrosis or hemorrhage in the tissue sections examined (Fig. 3).

In domestic pigs, porcine stress syndrome has been reported as one of the causes of sudden death, which is linked to a single point mutation in the skeletal muscle ryr gene [4]. However, there is no report about the stress-induced responses of the microminipig. In this case, ST-segment elevation was observed in leads II, III and aVF, suggesting the presence of transmural ischemia in the inferior myocardial wall, which may be supported by the regional wall-motion abnormality in the echocardiography. There are several known etiologies that can induce transmural ischemia, i.e. coronary artery occlusion by embolism, dissection, thrombus and/or vasospasm, etc. [1, 2, 7]. In our case, coronary artery occlusion by embolism, dissection or thrombus was not identified by macroscopic pathological observation of the heart. No histological changes indicating acute myocardial infarction were observed in the tissue sections that were obtained $1 \mathrm{hr}$ after the ST-segment elevation. The tip of catheter was placed in the left ventricle without fail, since the left ventricular pressure was measured. Thus, there was no possibility of obstruction at the inlet of coronary artery by "Amplatz catheter" itself. More importantly, we speculate that during the insertion of the catheter into the left ventricle, it might have injured the inlet of the right coronary artery, which would trigger the vasospasm. In addition, side effects of propofol and/or individual factors like low blood pressure could also be considered as substrates for the attack. While coronary artery vasospasm has been reported in the

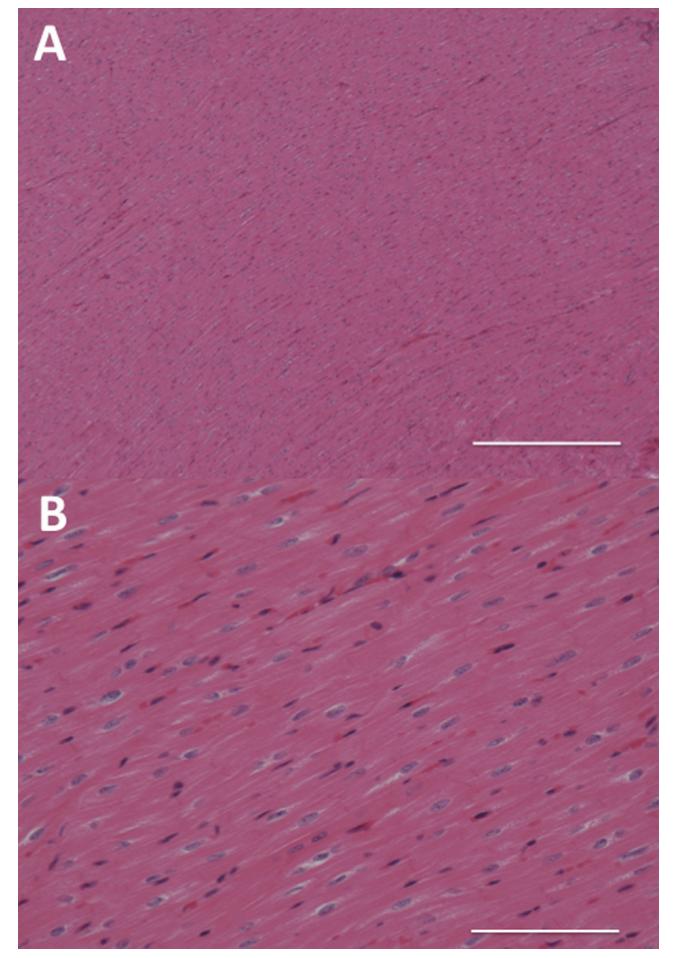

Fig. 3. Microscopic study. (A) The myocardium of inferior wall of the left ventricle at risk for ischemia is composed of bundles of cardiomyocytes, which are regularly arranged with a portion containing delicate blood vessels. There was no finding showing the presence of inflammation, necrosis and hemorrhage. Scale bar: $1 \mathrm{~mm}$. (B) Higher magnification of (A). The individual cardiomyocyte has central nucleus with a clear zone. Lack of inflammation, necrosis or hemorrhage in the myocardium indicated absence of acute myocardial infarction. Scale bar: $200 \mu \mathrm{m}$. 
atherosclerotic miniature pig [9], this is the first report that described feasible induction of coronary artery vasospasm in the healthy normal microminipig, which may partly explain the onset mechanism of a sudden death in swine. However, incidence as well as reproducibility of this attack still remains unknown.

ACKNOWLEDGMENTS. This study was supported in part by JSPS KAKENHI (\#25460344), MEXT KAKENHI (\#S1101016) and AMED Grant (\#AS2116907E). We thank Ms. Misako Nakatani, Mr. Takuya Kishie, Miss Mayuko Okamura and Miss Azajargal Enkhsakhan for their technical assistance.

\section{REFERENCES}

1. Bonow, R. O., Mann, D. L., Zipes, D. P. and Libby, P. 2012. Cardiac arrest and sudden cardiac death. pp. 845-884. In: Braunwald's Heart Disease A Textbook of Cardiovascular Medicine, 9th ed. (Braunwald, E, ed.), Elsevier, Philadelphia.

2. Camaro, C. and Aengevaeren, W. R. M. 2009. Acute myocardial infarction due to coronary artery embolism in a patient with atrial fibrillation. Neth. Heart J. 17: 297-299. [Medline] [CrossRef]

3. de Groot, J., Ruis, M. A., Scholten, J. W., Koolhaas, J. M. and Boersma, W. J. 2001. Long-term effects of social stress on antiviral immunity in pigs. Physiol. Behav. 73: 145-158. [Medline] [CrossRef]

4. Fujii, J., Otsu, K., Zorzato, F., de Leon, S., Khanna, V. K., Weiler, J. E., O'Brien, P. J. and MacLennan, D. H. 1991. Identification of a mutation in porcine ryanodine receptor associated with malignant hyperthermia. Science 253: 448-451. [Medline] [CrossRef]
5. Kawaguchi, H., Miyoshi, N., Miura, N., Fujiki, M., Horiuchi, M., Izumi, Y., Miyajima, H., Nagata, R., Misumi, K., Takeuchi, T., Tanimoto, A. and Yoshida, H. 2011. Microminipig, a non-rodent experimental animal optimized for life science research:novel atherosclerosis model induced by high fat and cholesterol diet. J. Pharmacol. Sci. 115: 115-121. [Medline] [CrossRef]

6. Miyoshi, N., Horiuchi, M., Inokuchi, Y., Miyamoto, Y., Miura, N., Tokunaga, S., Fujiki, M., Izumi, Y., Miyajima, H., Nagata, R., Misumi, K., Takeuchi, T., Tanimoto, A., Yasuda, N., Yoshida, H. and Kawaguchi, H. 2010. Novel microminipig model of atherosclerosis by high fat and high cholesterol diet, established in Japan. In Vivo 24: 671-680. [Medline]

7. Munz, M. R., Faria, M. A., Monteiro, J. R., Aguas, A. P. and Amorim, M. J. 2011. Surgical porcine myocardial infarction model through permanent coronary occlusion. Comp. Med. 61: 445-452. [Medline]

8. Salak-Johnson, J. L. and McGlone, J. J. 2007. Making sense of apparently conflicting data: stress and immunity in swine and cattle. J. Anim. Sci. 85 Suppl: E81-E88. [Medline] [CrossRef]

9. Shimokawa, H., Tomoike, H., Nabeyama, S., Yamamoto, H., Araki, H., Nakamura, M., Ishii, Y. and Tanaka, K. 1983. Coronary artery spasm induced in atherosclerotic miniature swine. Science 221: 560-562. [Medline] [CrossRef]

10. Sugiyama, A., Nakamura, Y., Akie, Y., Saito, H., Izumi, Y., Yamazaki, H., Kaneko, N. and Itoh, K. 2011. Microminipig, a non-rodent experimental animal optimized for life science research: in vivo proarrhythmia models of drug-induced long QT syndrome: development of chronic atrioventricular block model of microminipig. J. Pharmacol. Sci. 115: 122-126. [Medline] [CrossRef]

11. Swindle, M. M., Makin, A., Herron, A. J., Clubb, F. J. Jr. and Frazier, K. S. 2012. Swine as models in biomedical research and toxicology testing. Vet. Pathol. 49: 344-356. [Medline] [CrossRef] 